Revista Iberoamericana, Vol. LXXIX, Núm. 242, Enero-Marzo 2013, 257-264

\title{
TRAYECTORIAS, DESAFÍOS Y NUEVOS PARADIGMAS EN LOS ESTUDIOS CULTURALES LATINOAMERICANOS
}

\author{
POR \\ Arturo Arias \\ University of Texas, Austin
}

Ya hace varios años que George Yúdice y otros académicos que se distinguieron en los debates estadounidenses sobre este tema durante la década de los noventa, hablaron de la encrucijada de los estudios latinoamericanos luego del encuentro de LASA de 2001 y del ataque a las torres gemelas (Yúdice 449). De hecho, el artículo de Yúdice y otros artículos que igualmente perfilaban su ocaso y decadencia, y para los cuales Alberto Moreiras hasta seleccionó un epitafio del poeta español José Ángel Valente, fueron recogidos en un número especial de la Revista Iberoamericana en 2003. ${ }^{1}$ ¿Por qué entonces hablar ahora de estudios culturales en Centroamérica? La anterior no es una pregunta retórica. ¿Representa esto un nuevo ejemplo del atraso característico de la región, ya no sólo frente al mundo metropolitano occidental sino incluso frente a los centros hegemónicos de la misma periferia? ¿Es éste un ejemplo más de lo que anteriormente he denominado "la marginalidad de la marginalidad"? ¿Otra copia barata del consumismo cultural en el cual Centroamérica se inicia, una vez más, con un producto ya caduco que llega a sus puertos con todo el detritus descartable que el centro exporta para sacarle una última e ínfima ganancia a sus productos con fechas vencidas?

Me parece que si bien algunos cuantos rasgos de lo anterior podrían inevitablemente estar presentes en este bricolage que estamos recién denominando "estudios culturales centroamericanos”, esta frase se convierte para mí más bien en un tropo de una cierta voluntad crítica que justificaría su existencia. En ese sentido, una reflexión personal no deja de ser útil. Desde mi llegada a los Estados Unidos, luego de la derrota de la revolución guatemalteca, a mí me interesaron lo que ahora se denomina "estudios culturales” no porque ya estuvieran parcialmente institucionalizados en la academia

\footnotetext{
1 Véase el volumen LXIX/203 de abril-junio 2003 de Revista Iberoamericana. El número especial, coordinado por Alicia Ríos, Ana del Sarto y Abril Trigo, se titula "Los estudios culturales latinoamericanos hacia el siglo XXI”.
} 
estadounidense y que yo quisiera adherirme a la moda académica de ese entonces. Me interesaba más bien la continuidad con mi propia trayectoria, que se había iniciado en París en los años setenta con la sociología de la literatura en el sentido de Lucien Goldmann, había adquirido los matices pos-althusserianos de Terry Eagleton con cierta dosis gramsciana bajo la influencia de mi mentor, Luis Bocaz, quien también empujó la continuidad de cierto pensamiento latinoamericanista que atravesaba la obra de figuras tan disímiles como Mariano Picón Salas, Celso Furtado, Fernando Henrique Cardoso, Enzo Falletto, Tulio Halperín Donghi, Darcy Ribeiro y el centroamericano Edelberto Torres Rivas, además de la de críticos literarios tales como Antonio Candido, Ángel Rama y Roberto Fernández Retamar, para luego deslizarse hacia una historia de las ideologías en el sentido de François Châtelet.

Asimismo, y a nivel meramente anecdótico, Bocaz era íntimo amigo del poeta salvadoreño Roberto Armijo, con quien yo también guardaba amistad. En esa línea empezamos a trazar una genealogía del pensamiento centroamericanista en la cual incluíamos al Pop Wuj, Bernal Díaz del Castillo, Fuentes y Guzmán, Landívar, del Valle y Cardoza y Aragón, entre otros. ¿Qué significaba esta constelación de nombres, este cruce de contribuciones y de ejes direccionales en una relativa indeterminación epistemológica? Era sin lugar a dudas un anhelo por establecer una línea de pensamiento que articulara la producción de imaginarios colectivos y de códigos simbólicos de naturaleza cultural con su contexto político, histórico y social, para decirlo de una manera simple y comprensible. Se trataba de una búsqueda intuitiva por encontrar una reorientación sociosemiótica de la producción literaria que rompiera con la filología tradicional de corte franquista, y con el estructuralismo de corte francés, de moda hasta ese entonces, y que reducían ambos el texto literario a un mero objeto en sí mismo, alejado de toda contextualización socio-política. Era también una romántica búsqueda de respuesta a una entrevista con García Márquez que leí por ese entonces, quien afirmaba que la literatura no servía para absolutamente nada.

Estos lineamientos generales condujeron no sólo mi obra creativa, sino también mi producción crítica en una intersección de pensamiento intelectual y de práctica política que transitó por el movimiento revolucionario guatemalteco durante los años ochenta. Al dejar el mismo y reposicionarme como académico en los Estados Unidos en 1987, fue un movimiento cuasi natural el escenificar la convulsionada conflictividad social de mi región dentro del nuevo aparato disciplinario al cual me sometía. Fue así como noté de inmediato que en los debates de la mencionada época que lideraban nuestro campo, expresando no sólo las modas teóricas, sino también cierto afán de figuración por parte de algunas estrellas glamorosas de nuestra disciplina que desplegaban chapadas credenciales de izquierda sin haber militado nunca en revolución alguna,

ISSN 0034-9631 (Impreso) 
brillaba por su ausencia casi todo lo que se refiriera a lo centroamericano. ${ }^{2}$ El debate sobre la posmodernidad giraba en torno a centros urbanos sudamericanos; la discusión en torno a la naturaleza epistemológica del testimonio, fenómeno que bien hubiera podido concernir lo nuestro, comodificaba como ícono la figura de Menchú pero separaba a la misma de su contexto maya, ya que lo que les interesaba a sus teóricos en realidad era la fetichización de un género literario anti-literario desde donde se pudiera reconstruir la hegemonía política e intelectual de sus practicantes para justificar la ubicación enunciatoria del académico metropolitano, y no la referencialidad de su figura emblemática. El debate sobre la subalternidad recaía más en ocupar ese espacio teórico-metodológico dejado vacante por la "muerte" del marxismo y en asumir liderazgos dentro de la izquierda académica estadounidense que en vincularse solidariamente con la población subalterna de carne y hueso y con su producción cultural, constituyéndose así en esa fantasía disciplinaria de los intelectuales que señaló Gareth Williams, y que sirvió principalmente para promociones y escaladas salariales de los académicos mencionados con anterioridad, en su mayoría estadounidenses, que sólo vieron nuestros conflictos por televisión.

En todos estos casos, el académico centroamericano terminaba marginalizado por el académico metropolitano que, sin experiencia militante alguna ni práctica política conocida en país alguno de América Latina en esa conflictiva década de los ochentas, se erigía de súbito en ideólogo/dirigente de virtuales masas subalternizadas ubicadas en espacios igualmente enrarecidos en su éter referencial. La asombrosa urgencia vanguardista de muchos de estos profesores decía más acerca de su ansiedad por no perder su posición en los países metropolitanos que de los oscuros espacios de la subalternidad centroamericana abandonados a su suerte con el fin de las guerras civiles. Las obvias excepciones las constituían académicos quienes siendo de origen estadounidense en efecto vivieron los conflictos regionales desde dentro, tales como Marc Zimmerman, a manera de ejemplo, o bien figuras regionales como la nicaragüense Ileana Rodríguez quien, teniendo ya permanencia en la Universidad de Minnesota en 1979, optó por renunciar a la misma para insertarse en el proyecto sandinista. Su trayectoria denota la consecuencia ética y política de esa generación.

Como resultado, mi lucha personal a lo largo de los noventas se constituyó en un esfuerzo por hacer visible la centroamericanidad en el rancio ambiente teórico que entonces permeaba la academia estadounidense, re-entroncando así con el enfoque que había caracterizado mi producción. Debido a esto, embarcarme en lo que de manera

2 Me refiero aquí a académicos circunscritos al ambiente estadounidense, la mayoría de ellos de dicha nacionalidad, opinando con lujo de autoridad sobre temas políticos internos a Centroamérica hacia el final de los años ochenta, a diferencia del momento actual en el cual la militancia política es apenas un dato arqueológico ya que carece de presencia en la cotidianidad de buena parte de los intelectuales centroamericanos dentro y fuera de la región.

Revista Iberoamericana, Vol. LXXIX, Núm. 242,
ISSN 0034-9631 (Impreso) 
muy genérica se iba denominando como "estudios culturales latinoamericanos" fue un impreciso desliz que sucedió tan solo porque me ofreció mejores condiciones para el análisis de las culturas marginales conforme desarrollaba mi propio trabajo, problematizando la producción literaria centroamericana, la emergente producción centroamericana-americana que ya aparecía en el seno de la diáspora, y la gradual emergencia de la nueva cultura maya que también crecía como gigante frente a mis ojos. En otras palabras, este campo me proporcionó un espacio hermenéutico y teórico para acomodar mis intereses de largo plazo en la relación cultura/sociedad.

Como en el caso de otros investigadores que se han pronunciado a este respecto, a mí siempre me ha interesado reclamar la trayectoria política de los estudios culturales latinoamericanos, no como apéndice de los estudios culturales anglosajones iniciados por Stuart Hall en el Centro de Estudios Culturales Contemporáneos de la Universidad de Birmingham en los años cincuenta, cuya obra conocí ya tarde, o bien la corriente que se desprendió de Bourdieu en Francia paralelamente a mis propias búsquedas en la sociología de la literatura, ni como una imposición del mercado académico transnacional, sino más bien como la genealogía de un campo de reflexión que se origina en las propias crisis políticas de nuestro continente y en la necesidad de articular las mismas con sus imaginarios sociales y con la producción, circulación y consumo de sentido que se deriva de ellas.

De hecho me parece que es un trabajo que bien podría iniciarse con Andrés Bello en el continente y con José Cecilio del Valle en el caso de las nuevas repúblicas centroamericanas, y que se extiende en el tiempo, pasando por José Martí, José Enrique Rodó, Alfonso Reyes y Pedro Henríquez Ureña, para sólo mencionar emblemáticamente algunos nombres, antes de llegar a las metodologías innovadoras en las ciencias sociales de los sesentas, tales como la teoría de la dependencia, del colonialismo interno, o la teología de la liberación, que empezaron a sistematizar una forma de pensamiento original y originaria de nuestro continente, y que tuvieron su continuidad en la subalternidad, la colonialidad del poder, la transmodernidad y el posoccidentalismo, la colonialidad del saber, la geopolítica del conocimiento y el poscolonialismo indígena, entre otros, que emergieron en los noventas dentro de esa misma genealogía. Julio Ramos ha sido ya citado por decir hace varios años que la diferencia entre el pensamiento latinoamericanista tradicional y los estudios culturales latinoamericanos era que el primero creía en la capacidad integrativa de las literaturas nacionales y del arte, mientras que los estudios culturales las criticaban como aparatos de poder (36). Pero Trigo señala que las prácticas del conocimiento y las instituciones latinoamericanas siempre han sido heterogéneas e irreducibles a los principios de autonomía que limitaron las disciplinas en los Estados Unidos o en Francia. De allí que el papel seminal de figuras como las mencionadas, trabajando en los intersticios del ensayo con mecanismos y formas de conocimiento transdisciplinarios, justifique su

\footnotetext{
Revista Iberoamericana, Vol. LXXIX, Núm. 242, Enero-Marzo 2013, $257-264$
ISSN 2154-4794 (Electrónico)
} 
reconocimiento como precursores de los estudios culturales latinoamericanos (Trigo, "General Introduction" 6).

$\mathrm{Si}$ en el caso centroamericano tenemos algo en común con los orígenes anglosajones del modelo de Hall, esta similitud se encontraría más bien en que, al igual que en su caso, nosotros también llegamos hasta los estudios culturales desde una tradición eminentemente marginal, marginal incluso dentro de las corrientes críticas latinoamericanas, y que, al igual que los de Birmingham, nuestro compromiso con el campo cultural fue la manifestación de un repliegue táctico, cuando nuestro quehacer político fue desterritorializado por la derrota revolucionaria. Esta última significó un exilio diaspórico y la búsqueda de mecanismos para hacer política centroamericana por otros medios, terminando así en un ambiguo espacio académico por omisión en el cual la política emancipatoria de la cual muchos de nosotros participamos se redujo a una representación simbólica identitaria y de reconstrucción del imaginario de la memoria revolucionaria desde nuestros espacios exílicos. Pero, a su vez, y gracias a la tecnología y al uso creativo de los espacios virtuales, también se tradujo en un mecanismo para reactivar un pensamiento político nuevo en nuestros espacios de acción. Es decir, enraizados tan sólo en representaciones locales simbólicas, pudimos reciclar nuestra memoria cultural para reconfigurar nuestra identidad política, por escindida o conflictiva que fuera, en los puntos inestables de los espacios globalizados, problematizando los imaginarios que organizan, estructuran y reproducen las escurridizas realidades sociales, políticas y culturales de la región. En buena medida, es esto lo que estamos nombrando ahora como "estudios culturales centroamericanos".

En este último sentido, la trayectoria centroamericana correría en una situación paralela a la delineada en The Latin American Cultural Studies Reader, publicado en inglés en 2004. Según el mismo, la definición del campo es tan sólo operativa. Se refiere a un campo de investigación históricamente configurado desde la tradición crítica latinoamericana y en diálogo constante, a veces conflictivo, con las escuelas de pensamiento occidentales (Trigo, “General Introduction” 5). Más allá de problematizar su contextualización sociohistórica disputada, su relación con los estudios culturales angloamericanos y sus continuidades sociohistóricas, la introducción de la mencionada antología también problematiza las fracturas sociopolíticas, el pensamiento latinoamericano indisciplinado -por lo cual entiende que está ubicado fuera de las disciplinas académicas tradicionales- y los cambios epistémicos de las disciplinas y las formaciones discursivas. Concluye con un esquema o mapa visual al cual le da el nombre de "constelación cognitiva", que cubre lo que a su entender son los tres momentos de los estudios culturales latinoamericanos: el de los precursores -dentro del cual incluye las obras de Fernández Retamar, Rama, Candido, Ribeiro y Cornejo Polar-, el de las fundaciones -donde ubica a Mignolo, Brunner, Monsiváis, Sarlo, Schwarz, García Canclini, Martín Barbero y Franco-, y el de las prácticas y polémicas,

\footnotetext{
Revista Iberoamericana, Vol. LXXIX, Núm. 242,
ISSN 0034-9631 (Impreso)
} 
en el cual elabora una lista más larga dentro de la cual podríamos mencionar a Beverley, Richard, de la Campa, Moraña, Moreiras y Yúdice.

Como podemos observar, con la posible salvedad de Yúdice, no encontramos en la lista a ningún centroamericano, pese a que la problemática de las prácticas incluye el poscolonialismo y el posoccidentalismo, los estudios trasnacionales, la subalternidad y la crítica cultural en general-temas todos de urgente relevancia para lo centroamericano. Sin embargo, al analizar el volumen de The Latin American Cultural Studies Reader, vemos lo que a mi modo de ver es una diferencia importante entre el trabajo de los autores por ellos antologados y el de muchos de los críticos centroamericanos. La gran mayoría de los autores antologados presenta ya sea una visión general del campo, o bien una teorización crítica de esta misma totalidad, pero no aparecen lo que podríamos llamar, por falta de mejor terminología, análisis concretos de casos concretos. En cambio, lo que parecería interesarnos a los centroamericanos sería precisamente esta especificidad que nos nombra, que nos hace visibles ante el mundo, que explicita nuestras subjetividades individuales y sociales, que problematiza nuestros imaginarios y espacios de representación concretos saturados de elementos simbólicos que aluden a nuestro pasado reciente. Es allí donde la experiencia concreta vivida durante el presente transnacional y globalizado se confunde con la experiencia acumulada en la memoria de las guerras, compaginada con la intimidad y con la cotidianidad, confluyendo todo en una memoria cultural producida por una comunidad regional concreta a través de una experiencia colectiva acumulada, la cual genera una memoria cultural práctica y performativa que se distingue de la de otras partes del continente. Para lograr estas metas génericas y un tanto difusas, hemos todos empezado a operar instintivamente en un proceso de acercamiento gradual a variadas metodologías transdisciplinarias, técnicas, teorías y métodos especulativos para defender nuestros proyectos, sin mayor acercamiento entre los que seríamos practicantes de esta variante que una tenue conformación de redes. No hemos interactuado como movimiento explícito en el sentido en el cual operó el grupo de estudios subalternos, ni como miembros de una forma disciplinaria coherente y bien definida de un campo de trabajo previamente teorizado y problematizado.

Lo anterior no tiene que ser visto como problemático, siempre y cuando no nos arrimemos a la superficialidad, no forcemos las fronteras entre los campos de estudios con simpleza voluntarista, no hablemos sólo de nosotros mismos para satisfacer, como diría Mignolo, "las exigencias de 'autenticidad' disciplinaria” (412) o, peor, caigamos en la versión burocratizada de los estudios culturales que le hace el juego a la universidad corporativa y a las políticas neoliberales. Lo que distingue los estudios culturales centroamericanos, a mi modo de ver, no es ni su teorización que sería hasta hoy casi inexistente si la midiéramos desde la perspectiva de los Cultural Studies de la academia estadounidense, sus fundamentos epistemológicos que también brillarían

\footnotetext{
Revista Iberoamericana, Vol. LXXIX, Núm. 242, Enero-Marzo 2013, $257-264$
ISSN 2154-4794 (Electrónico)
} 
por su ausencia desde la anterior perspectiva, su rendimiento concreto que apenas si empieza a ser visible en los espacios académicos metropolitanos, ni una metodología que calque las prácticas y polémicas de los estudios culturales latinoamericanos, sino, por encima de todo ello, su voluntad crítica por hacer el balance de y extraerle sentido a la experiencia guerrillera vivida en el pasado reciente y a sus registros e imaginarios sociohistóricos. ${ }^{3}$

Lo anterior constituyó el momento más transcendental de nuestra modernidad. El más trágico, el más agonístico, pero cuyo impacto final estamos aún lejos de percibir o comprender incluso. Es una experiencia que todavía articula nuestros fenómenos contemporáneos más transcendentales, desde el resurgimiento del movimiento maya y la transformación de TACA en monopolio centroamericano hasta la migración masiva hacia los Estados Unidos que ha afectado tanto a nuestra región como a la sede imperial, en cuyas entrañas navegamos a tambor batiente, produciendo nuevos fenómenos culturales centroamericano-americanos que pueden oscilar desde el grupo de poesía performativa EpiCentro hasta la Mara Salvatrucha, entre otros.

Dadas las referencias anteriores, entiendo los estudios culturales centroamericanos no sólo como un nuevo saber transdisciplinario, como una dimensión críticoestética de la cultura, como una desterritorialización académica o como una nueva forma de conocimiento, sino como otra variante de lo que Mabel Moraña llamó "la recuperación de lo político” (429), y que Nelly Richard definió como "una dimensión que siga comprometida con las operaciones de riesgo mediante las cuales cada práctica estética o cultural decide a partir de sus batallas la forma para subvertir los pactos de entendimiento oficial con nuevas maneras de ser, de ver y de leer" (445). Ambas critican el protagonismo intelectual desde las posiciones de la centralidad metropolitana y el privilegio que esto representa.

En el fondo, sigue siendo la práctica cultural subversiva y transgresora del intelectual ético. La conducta ética, con su concomitante teoría de las emociones y de nuestros espacios afectivos, tiene un vínculo directo con los estudios culturales centroamericanos y con las implicaciones igualmente éticas de embarcarse en ellos. Esto se debe a que al reflexionar sobre el tema, es inevitable llegar a la conclusión de que, para muchos de nosotros, nuestro interés en este monstruo de siete cabezas que hoy estamos configurando disciplinariamente y que corremos el riesgo de institucionalizar,

3 Como señala Leonel Delgado Aburto, la labor de numerosos intelectuales centroamericanos forma parte del trabajo generado en espacios tales como las universidades jesuitas, el Centro de Investigaciones Regionales Mesoamericanas CIRMA, en Antigua Guatemala, FLACSO, o bien por medio de proyectos interdisciplinarios tales como el HILCAS, publicado en la revista Istmo. Los mismos demuestran que existe teorización con profundidad en Centroamérica. La misma tiene lugar desde el espacio que ocupan los intelectuales al interior de las sociedades centroamericanas, a veces bajo grandes niveles de violencia, como es el caso de Honduras en la actualidad (comunicación personal, 7 diciembre 2009).

ISSN 0034-9631 (Impreso) 
partió de cómo vivimos en el plano emocional las experiencias políticas del istmo en décadas recién pasadas, a manera de explorar las posibilidades de construcción de un ethos alternativo desde los intersticios de la memoria rota. En este sentido, los estudios culturales centroamericanos son también un intento por reimaginar quiénes somos como sujetos y por reubicarnos como sujetos globalizados arrancados de sus apegos y de su cultura en este heterotópico espacio pos-neoliberal y en este tiempo pos-Bush, en el cual blandimos nuestros ocultos espacios fantasmáticos como único salvavidas y como última trinchera.

\section{BiBLIOGRAFÍA}

Mignolo, Walter. "Los estudios culturales: geopolítica del conocimiento y exigencias/ necesidades institucionales”. Revista Iberoamericana LXIX/203 (2003): 401-16.

Moraña, Mabel. "Estudios culturales, acción intelectual y recuperación de lo político”. Revista Iberoamericana LXIX/203 (2003): 425-30.

Ramos, Julio. "El proceso de Alberto Mendoza: poesía y subjetivación”. Revista de Crítica Cultural 13 (1996): 34-41.

Richard, Nelly. "El conflicto entre las disciplinas". Revista Iberoamericana LXIX/203 (2003): 441-48.

Ríos, Ana del Sarto, y Abril Trigo, eds. Número especial dedicado a "Los estudios culturales latinoamericanos hacia el siglo XXI". Revista Iberoamericana LXIX/203 (2003).

Trigo, Abril. "General Introduction”. The Latin American Cultural Studies Reader. Ana del Sarto, Alicia Ríos y Abril Trigo, eds. Durham: Duke UP, 2004. 1-14.

"Why Do I Do Cultural Studies?” Journal of Latin American Cultural Studies 9/1 (2000): 73-93.

Yúdice, George. "Los estudios culturales en la encrucijada de la incertidumbre". Revista Iberoamericana LXIX/203 (2003): 449-64.

$\begin{array}{llllll}\text { ISSN 2154-4794 (Electrónico) } & \text { Revista Iberoamericana, Vol. LXXIX, Núm. 242, } & \text { Enero-Marzo 2013, } & \text { 257-264 } \\ \text { ISSN 0034-9631 (Impreso) } & & & \end{array}$ 